\title{
Fitotoxicidade do mercúrio sobre a qualidade fisiológica em sementes de saboneteira (Sapindus saponaria L.) submetidas à escarificação mecânica
}

\author{
Bruno Oliveira Lafetá1*, Lucimeiri Alves Nascimento² ${ }^{2}$, Carlos Henrique Souto Azevedo ${ }^{3}$, Tamires Mousslech \\ Andrade Penido ${ }^{4}$, Luiz Felipe Ramalho de Oliveira ${ }^{5}$
}

\begin{abstract}
Resumo
A contaminação de solos por mercúrio é um problema ambiental grave, com potencial de biomagnificação em cadeias alimentares e danos à saúde humana. O objetivo do presente trabalho foi avaliar o efeito de diferentes concentrações de $\mathrm{HgO}$ na germinação e desenvolvimento de plântulas de Sapindus saponária submetidas a escarificação mecânica. O experimento foi instalado em DIC com quatro repetições de 25 sementes, no esquema fatorial $4 \times 2$, sendo estudado o efeito de quatro concentrações de $\mathrm{HgO}$ em vermiculita $\left(\mathrm{C} 1-0,000 \mathrm{~g} / \mathrm{cm}^{3} ; . \mathrm{C} 2-0,025 \mathrm{~g} / \mathrm{cm}^{3} ; \mathrm{C} 3-0,050 \mathrm{~g} / \mathrm{cm}^{3} \mathrm{e}\right.$ $\mathrm{C} 4-0,075 \mathrm{~g} / \mathrm{cm}^{3}$ ) e de dois pré-tratamentos (P1 - Testemunha: sementes com tegumento intacto e P2 - escarificação mecânica do tegumento em esmeril elétrico). Avaliaram-se atributos relacionados à germinação e desenvolvimento de plântulas. Realizaram-se teste $\mathrm{F}$, análise de regressão e teste $t$ pareado, todos a 5,0 \% de significância estatística. A escarificação mecânica do tegumento com esmeril elétrico favoreceu a embebição das sementes (100,0 \%), germinação $(85,25 \%)$ e emissões de raízes laterais $(70,0 \%)$ e de parte aérea $(76,25 \%)$. A presença de mercúrio na vermiculita prejudicou o desenvolvimento das plântulas. Conclui-se que a escarificação mecânica do tegumento com esmeril elétrico pode ser indicado para superar a dormência das sementes de $S$. saponaria. Esta espécie tolera pequenas concentrações de $\mathrm{HgO}\left(0,0045 \mathrm{~g} / \mathrm{cm}^{3}\right)$ sem causar maiores danos ao seu crescimento e acúmulo de massa verde.
\end{abstract}

Palavras-chave: Desenvolvimento de plântulas. Germinação. Óxido de mercúrio II.

\section{Phytotoxicity of mercury and mechanical scarification in Sapindus saponaria L. propagation}

\footnotetext{
Abstract

${ }^{1}$ Instituto Federal de Educação, Ciência e Tecnologia de Minas Gerais. São João Evangelista, MG. Brasil. http://orcid.org/0000-0003-2913-6617

${ }^{2}$ Instituto Federal de Educação, Ciência e Tecnologia de Minas Gerais. São João Evangelista, MG. Brasil. https://orcid.org/0000-0002-5154-9023

${ }^{3}$ Instituto Federal de Educação, Ciência e Tecnologia de Minas Gerais. São João Evangelista, MG. Brasil. https://orcid.org/0000-0002-2031-4280

${ }^{4}$ Universidade Federal dos Vales do Jequitinhonha e Mucuri. Diamantina, MG. Brasil.

https://orcid.org/0000-0001-7764-8532

${ }^{5}$ Universidade Federal dos Vales do Jequitinhonha e Mucuri. Diamantina, MG. Brasil.

http://orcid.org/0000-0003-2579-9341

*Autor para correspondência: bruno.lafeta@ifmg.edu.br
}

Soil contamination by mercury is a serious environmental problem, with potential for food chain biomagnification and damage to human health. This study aimed to evaluate the effect of different concentrations of $\mathrm{HgO}$ on germination and seedling development of Sapindus saponaria submitted to mechanical scarification. The experiment was established in completely randomized design with four repetitions of 25 seeds, in 4 x 2 factorial arrangement, being studied the effect of four concentrations of $\mathrm{HgO}$ in vermiculite $\left(\mathrm{C} 1-0.000 \mathrm{~g} / \mathrm{cm}^{3} ; . \mathrm{C} 2-0.025 \mathrm{~g} / \mathrm{cm}^{3} ; \mathrm{C} 3-0.050 \mathrm{~g}\right.$ / $\mathrm{cm}^{3}$ e $\mathrm{C} 4-0.075 \mathrm{~g} / \mathrm{cm}^{3}$ ) and two pre-treatments (P1 - Control: seeds with intact integument and P2 - mechanical scarification with electric emery). Attributes related to germination and seedling development were evaluated. F-test, regression analysis and paired t-test were performed, all of the $5.0 \%$ statistical significance. Mechanical scarification with electric emery favored seed imbibition (100.0\%), germination (85.25\%) and emissions of lateral roots $(70.0$ $\%)$ and shoot (76.25 \%). The presence of mercury in vermiculite impaired seedling development. It was concluded

Recebido para publicação em 02 de novembro de 2019. Aceito para publicação em 19 de dezembro de 2019. e-ISSN: 2447-6218 / ISSN: 2447-6218 / (C) 2009, Universidade Federal de Minas Gerais, Todos os direitos reservados. 
da Silveira, A. B. et al.

that mechanical scarification with electric emery can be indicated to overcome seed dormancy of $S$. saponaria. This species tolerate low concentrations of $\mathrm{HgO}\left(0.0045 \mathrm{~g} / \mathrm{cm}^{3}\right)$ without causing further damage to its growth and accumulation of green mass.

Keywords: Seedling development. Germination. Mercury II oxide.

\section{Introdução}

A contaminação de solos por metais pesados é um problema ambiental grave que deve ser tratado com cautela pela sociedade. Metais podem ser absorvidos por vegetais e ingressar na cadeia alimentar, prejudicando a saúde humana (Kehrig et al., 2011).

O mercúrio $(\mathrm{Hg})$ é um metal não essencial para as plantas, geralmente tóxico mesmo em baixas concentrações (White e Brown, 2010). Possui número atômico 80 , densidade de $13,58 \mathrm{~g} / \mathrm{cm}^{3}$ na forma líquida e pode ser comercializado como óxido de mercúrio II ( $\mathrm{HgO})$, que possui massa molar de $216,6 \mathrm{~g} / \mathrm{mol}$ e aspecto físico de pó fino e coloração laranja (Damas et al., 2014). As principais fontes poluidoras de mercúrio são provenientes dos garimpos de ouro e fontes difusas como a deposição de resíduos sólidos em aterros sanitários, queima de combustíveis fósseis e produção de aço utilizando sucata como matéria prima (Micaroni et al., 2000).

O metal pesado pode inibir a respiração e causar danos ao sistema fotossintético vegetal (Milner e Kochian, 2008; Voicu e Zwiazek, 2010). A primeira barreira de íons metálicos via simplasto é a membrana plasmática de células radiculares. Concentrações tóxicas de metal estimulam a oxidação lipídica da membrana e desequilíbrio iônico no citoplasma (Kenderesová et al., 2012). Normalmente, plantas terrestres possuem uma capacidade limitada de tolerar solos com excesso de metais pesados, armazenando íons na parede celular das raízes e vacúolos (Milner e Kochian, 2008; Conn e Gilliham, 2010). A compartimentação do metal dentro das células é fundamental para manter baixa sua concentração no citoplasma (Kenderesová et al., 2012).

A regulação do influxo e efluxo celular de metal é responsável pela sua translocação para o tecido ou órgão onde será armazenado e, em alguns casos, inativado (Kenderesová et al., 2012). Segundo Conn e Gilliham (2010), a sensibilidade de plantas a esses metais pode ser influenciada por fatores moleculares (aminoácidos, ferritinas e ácidos orgânicos) e fisiológicos (estresse, absorção de metais através da parede celular e/ou de ligação a exsudatos extracelulares).

Espécies autóctones de rápido crescimento e acumuladoras de metais pesados minimizam custos com fitorremediação e preservam a atividade biológica e estrutural de solos (Cicatelli et al., 2010). Várias espécies evoluíram e se adaptaram a solos metálicos e, exemplos podem ser observados nas famílias Asteraceace, Brassicaceae, Caryophyllaceae, Fabaceae, Poaceae, Salicaceae,
Sapindaceae e Violaceae (Milner e Kochian, 2008; Marmiroli et al., 2011; Noriega-Luna et al., 2016).

Sapindus saponaria L. (Sapindaceae), conhecida popularmente como saboneteira, saboneteiro ou saboeiro, é uma espécie de porte arbóreo, heliófita e nativa de áreas úmidas do Brasil (Albiero et al., 2001; Grisi et al., 2013; Rashed et al., 2013). Pertence ao grupo ecológico das secundárias tardias e é amplamente empregada em planos para a revegetação de áreas degradadas e arborização de centros urbanos (Silva et al., 2016).

Sementes de $S$. saponaria apresentam dormência física causada pela impermeabilidade do tegumento à penetração de água. Desta forma, mesmo com o embrião totalmente formado, não ocorre a embebição de água pelo material propagativo (Cook et al., 2008; Turner et al., 2009; Oliveira et al., 2012). Essa dormência pode ser superada com a escarificação mecânica do tegumento e a germinação, favorecida por temperaturas entre $25 \mathrm{e}$ $35^{\circ} \mathrm{C}$ (van Klinken; Flack, 2005).

A dormência é uma estratégia evolutiva que distribui a germinação ao longo do tempo, estabelecendo plantas em condições ambientais favoráveis para seu crescimento (Copete et al., 2011; Toorop et al., 2012; van Klinken et al., 2008). Entretanto, pode causar atrasos e desuniformidade na germinação (Wagmann et al., 2012).

Informações sobre a propagação de espécies nativas em ambientes perturbados com a presença de metais pesados são necessárias para o desenvolvimento de técnicas de fitorremediação e prevenção de áreas sujeitas à contaminação. $O$ presente trabalho teve como objetivo avaliar o efeito de diferentes concentrações de $\mathrm{HgO}$ na germinação e desenvolvimento de plântulas de Sapindus saponaria submetidas a escarificação mecânica.

\section{Material e métodos}

Foram selecionadas árvores de $S$. saponaria para a coleta de frutos em fragmentos de Mata Atlântica, sob as coordenadas de $18^{\circ} 32^{\prime} 44,99^{\prime \prime}$ de latitude Sul e $42^{\circ} 45^{\prime} 17,64$ ' de longitude Oeste (Datum Sirgas 2000), em área do Instituto Federal de Educação, Ciência e Tecnologia de Minas Gerais - Campus São João Evangelista (IFMG/SJE). O clima da região é o temperado chuvoso-mesotérmico, classificado como Cwa pelo sistema de Köppen (com inverno seco e verão chuvoso). As médias anuais de precipitação e temperatura são de $1377 \mathrm{~mm}$ e $20,2^{\circ} \mathrm{C}$, respectivamente (Climate-data.org, 2019). 
da Silveira, A. B. et al.

As árvores selecionadas apresentavam altura total de 5 a $7 \mathrm{~m}$, diâmetro a 1,30 $\mathrm{m}$ do solo superior a $20 \mathrm{~cm}$ e nenhum sinal aparente de injúrias ocasionadas pelo ataque de insetos ou doenças. A coleta dos frutos foi realizada diretamente na copa com auxílio de podão, restringindo-se àqueles de coloração marrom. Posteriormente, foram acondicionados em sacos de papel Kraft e conduzidos ao Laboratório de Sementes do IFMG/SJE para triagem. Essa foi realizada manualmente, isolando as sementes dos frutos e eliminando o material que possuía alguma injúria, atrofia ou ataque por insetos a fim de se obter uma melhor qualidade e pureza física dos lotes.

O teor de água das sementes foi determinado pelo método da estufa a $105 \pm 3^{\circ} \mathrm{C}$ por $24 \mathrm{~h}$, com quatro repetições de 25 unidades.

As sementes após a triagem foram desinfestadas com hipoclorito de sódio ( $\mathrm{NaClO}$ ), com 2,0\% de cloro ativo, a 5,0 \% (v/v) durante três min, depois lavadas com água destilada e colocadas para secar durante dez min sobre papel toalha. Optou-se pelo $\mathrm{NaClO}$ por se tratar de um composto químico contra proliferação bacteriana.

O trabalho foi conduzido em câmara de germinação do tipo Biochemical Oxigen Demand (BOD) com fotoperíodo contínuo $(24 \mathrm{~h})$ e temperatura de $31^{\circ} \mathrm{C}$, procedimento de rotina usado para espécies florestais pelo Laboratório de Sementes do IFMG/SJE. O delineamento experimental adotado foi o inteiramente casualizado com quatro repetições, no esquema fatorial 4 x 2 , sendo estudado o efeito de quatro concentrações de Óxido de Mercúrio II (HgO) em substrato (C1 - 0,000 g/ $\mathrm{cm}^{3}$;. C2 - 0,025 g/ $\mathrm{cm}^{3}$; C3 - 0,050 g/ $\mathrm{cm}^{3}$ e C4 - 0,075 g/ $\mathrm{cm}^{3}$ ) e dois pré-tratamentos (P1 - Testemunha: sementes com tegumento intacto e P2 - escarificação mecânica do tegumento em esmeril elétrico: as sementes foram friccionadas em esmeril elétrico com auxílio de um alicate na região oposta ao eixo-embrionário até o desgaste do tegumento, evitando, contudo danificar o embrião. A unidade experimental foi constituída por 25 sementes. Esta quantidade foi definida conforme a capacidade da caixa gerbox (transparente, com dimensçoes de $11 \times 11$ $\times 3,5 \mathrm{~cm}$ ), recipiente empregado para a semeadura de $S$. saponaria. A caixa gerbox foi escolhida com a finalidade de reduzir riscos com a saúde do avaliador e contaminação ambiental por $\mathrm{HgO}$.

Cada caixa gerbox foi previamente desinfestada com álcool etílico $70 \%$ (v/v) e preenchida com $200 \mathrm{~cm}^{3}$ de vermiculita expandida superfina. A mistura da vermiculita com o $\mathrm{HgO}$ foi realizada na caixa gerbox com auxílio de um bastão de vidro. A semeadura foi feita sobre a superfície do substrato umedecido. As caixas gerboxes foram fechadas com tampa própria e distribuídas aleatoriamente na BOD, totalizando 32 unidades experimentais.

As avaliações foram realizadas diariamente até a contagem final e estabilização de todos os atributos estudados (trigésimo dia), registrando número de sementes embebidas (Emb), germinação ( $G$, protrusão de radícula superior a $1,0 \mathrm{~cm}$ ) e emissões de parte aérea (EPA) e de raízes laterais (ERL). As sementes não embebidas foram consideradas duras, pois mantiveram o aspecto de recém semeadas. Calcularam-se os índices de velocidade da embebição (IVEmb) e da germinação (IVG) conforme a metodologia proposta por Maguire (1962).

Após a contagem final, tomaram-se das plântulas normais os comprimentos da raiz principal (CR) e da parte aérea (CPA) com um paquímetro digital de precisão 1/10 mm e, depois, obtida a relação CPA/CR. A massa verde de cada um desses componentes foi realizada com balança digital de 0,0001 g de precisão. Calculou-se a massa verde total (MVT) pela soma das massas do sistema radicular (MVR) e da parte aérea (MVPA). Considerou-se como plântula normal aquelas que apresentaram desenvolvimento radicular superior a 1,0 cm (Brasil, 2009).

Todos os dados expressos em porcentagem foram transformados em $\operatorname{arc}$ seno $\sqrt{x / 100}$ e o restante em $\sqrt{x}$ , a fim de atender aos critérios de normalidade segundo Lilliefors e homogeneidade por Cochran. Realizaram-se teste $\mathrm{F}$, regressão quadrática e teste $t$ pareado, todos a $5 \%$ de significância estatística. Na análise de regressão, foi usado o método dos mínimos quadrados ordinários (MQO). As análises estatísticas foram efetuadas com auxílio do software R versão 3.5.2 (R Core Team, 2018).

\section{Resultados e discussão}

O teor de água das sementes de $S$. saponaria foi de $12,72 \pm 6,1431 \%$. O efeito estatístico de pré-tratamento foi observado em todos os atributos avaliados ( $p \leq 0,05)$, exceto aqueles obtidos após a contagem final, realizada aos 30 dias (Tabela 1). Estes apresentaram significância em nível de concentrações, exceto o comprimento de parte aérea, cuja média foi de 20,66 \pm 6,1470 mm. As concentrações de $\mathrm{HgO}$ resultaram em crescimento diferenciado das plântulas de saboneteira. Em geral, os coeficientes de variação foram baixos e evidenciaram a precisão experimental.

A dormência tegumentar das sementes de $S$. saponaria foi comprovada face à dificuldade de embebição das sementes em água e, consequentemente, menor germinação no tratamento testemunha (Tabela 2). Foi necessária a escarificação do tegumento com esmeril elétrico para favorecer a entrada de água e trocas gasosas entre ambiente e embrião; 100,0 \% das sementes escarificadas tiveram embebição (IVEmb de 15,54) e 85,25 \% germinaram (IVG de 2,07). Essa impermeabilidade pode ser decorrente de um conjunto de células parenquimáticas dispostas em paliçada e de uma camada de cutícula, que protegem o embrião (Freitas et al., 2013). Corroborando com Albiero et al. (2001), que confirmaram a existência de várias camadas no tegumento das sementes de $S$. saponaria que poderiam limitar a absorção de água. 
da Silveira, A. B. et al.

Tabela 1 - Resumo da análise de variância, com os dados transformados, dos atributos avaliados até e após contagem final (30 dias) em sementes de S. saponaria

\begin{tabular}{|c|c|c|c|c|c|c|}
\hline \multirow{2}{*}{ F.V. } & \multicolumn{6}{|c|}{ 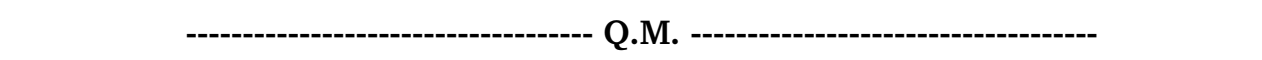 } \\
\hline & Emb & G & EPA & ERL & IVEmb & IVG \\
\hline Concentrações (c) & $25,89 \mathrm{~ns}$ & $24,19 \mathrm{~ns}$ & $36,44 \mathrm{~ns}$ & $49,12 \mathrm{~ns}$ & $0,15 n s$ & $0,02 \mathrm{~ns}$ \\
\hline Pré-tratamentos (p) & $12504,56^{*}$ & $4823,78^{*}$ & $3068,99 *$ & $2047,05^{*}$ & $3,33^{*}$ & $0,89 *$ \\
\hline $\mathrm{cxp}$ & $25,89 \mathrm{~ns}$ & $75,37 \mathrm{~ns}$ & $268,22 \mathrm{~ns}$ & $226,78 \mathrm{~ns}$ & $0,03 \mathrm{~ns}$ & $0,04 \mathrm{~ns}$ \\
\hline Resíduo & 22,14 & 59,33 & 268,80 & 302,78 & 0,06 & 0,04 \\
\hline \multirow[t]{2}{*}{ CV exp } & 6,70 & 13,72 & 31,71 & 36,35 & 6,67 & 16,95 \\
\hline & CR & CPA & $\mathrm{CPA} / \mathrm{CR}$ & MVR & MVPA & MVT \\
\hline Concentrações (c) & $63,63 *$ & $0,62 \mathrm{~ns}$ & $0,47^{*}$ & $0,04 *$ & $0,02^{*}$ & $0,01^{*}$ \\
\hline Pré-tratamentos (p) & $0,21 \mathrm{~ns}$ & $0,08 \mathrm{~ns}$ & $0,00 \mathrm{~ns}$ & $0,00 \mathrm{~ns}$ & $0,01 \mathrm{~ns}$ & $0,00 \mathrm{~ns}$ \\
\hline $\mathrm{cxp}$ & $0,12 \mathrm{~ns}$ & $0,45 \mathrm{~ns}$ & $0,01 \mathrm{~ns}$ & $0,00 \mathrm{~ns}$ & $0,00 \mathrm{~ns}$ & $0,00 \mathrm{~ns}$ \\
\hline Resíduo & 0,33 & 0,25 & 0,00 & 0,00 & 0,00 & 0,00 \\
\hline CV exp & 9,47 & 11,07 & 6,96 & 11,92 & 23,41 & 3,10 \\
\hline
\end{tabular}

*(p s 0,05). ns (p > 0,05). Os graus de liberdade foram 3, 1, 3 e 24 para concentrações, pré-tratamentos, interação e resíduo, respectivamente. Emb $=$ Embebidas. $\mathrm{G}=$ Germinação. $\mathrm{EPA}=$ Emissão de parte aérea. $\mathrm{ERL}=$ Emissão de raízes laterais. IVEmb = Índice de velocidade da embebição. IVG $=$ Índice de velocidade da germinação. $\mathrm{CR}=$ Comprimento da raiz principal. $\mathrm{CPA}=$ Comprimento da parte aérea. MVR $=$ Massa verde do sistema radicular. MVPA = Massa verde da parte aérea. MVT = Massa verde total.

Tabela 2 - Médias dos atributos avaliados até contagem final (30 dias) em sementes de $S$. saponaria

\begin{tabular}{|c|c|c|c|c|c|c|}
\hline \multirow{2}{*}{ Pré-tratamentos } & Emb & G & ERL & EPA & IVEmb & IVG \\
\hline & \multicolumn{6}{|c|}{--------------------- \% ---------------------- } \\
\hline $\mathrm{P} 1$ & $59,25 \mathrm{~b}$ & $48,00 \mathrm{~b}$ & $41,25 \mathrm{~b}$ & $44,75 \mathrm{~b}$ & $10,91 \mathrm{~b}$ & $1,19 \mathrm{~b}$ \\
\hline $\mathrm{P} 2$ & $100,00 \mathrm{a}$ & $85,25 \mathrm{a}$ & $70,00 \mathrm{a}$ & $76,25 \mathrm{a}$ & $15,54 \mathrm{a}$ & $2,07 \mathrm{a}$ \\
\hline
\end{tabular}

Médias seguidas pela mesma letra não se diferenciam pelo teste $\mathrm{F}(\mathrm{p}>0,05)$. Emb $=$ Embebidas. $\mathrm{G}=\mathrm{Germinação.} \mathrm{ER}=\mathrm{Emissão} \mathrm{de} \mathrm{raízes.} \mathrm{EPA}$ = Emissão de parte aérea. IVEmb = Índice de velocidade da embebição. IVG = Índice de velocidade da germinação. P1 = Testemunha: sementes com tegumento intacto. P2 = Escarificação mecânica com esmeril elétrico.

A dormência tegumentar das sementes de $S$. saponaria foi comprovada face à dificuldade de embebição das sementes em água e, consequentemente, menor germinação no tratamento testemunha (Tabela 2). Foi necessária a escarificação do tegumento com esmeril elétrico para favorecer a entrada de água e trocas gasosas entre ambiente e embrião; $100,0 \%$ das sementes escarificadas tiveram embebição (IVEmb de 15,54) e 85,25 \% germinaram (IVG de 2,07). Essa impermeabilidade pode ser decorrente de um conjunto de células parenquimáticas dispostas em paliçada e de uma camada de cutícula, que protegem o embrião (Freitas et al., 2013). Corroborando com Albiero et al. (2001), que confirmaram a existência de várias camadas no tegumento das sementes de $S$. saponaria que poderiam limitar a absorção de água.

A embebição tardia do tratamento testemunha provocou desuniformidade na sua germinação. A embebição das sementes escarificadas iniciou-se no primeiro dia de contagem, seguida da germinação (quinto dia) e emissões de parte aérea (oitavo dia) e de raízes laterais (nono dia). Mais emissões de raízes laterais (70,00 \%) e de parte aérea $(76,25 \%)$ foram observadas ao escarificar o tegumento das sementes. A frequência de plântulas foi maior nesse tratamento pré-germinativo, demonstrando potencial de estabelecimento no substrato. Assim, espera-se que a semeadura a lanço com sementes escarificadas de $S$. saponaria tenha mais sucesso na recomposição florestal que o uso de sementes com tegumento intacto.

A presença do mercúrio na vermiculita não afetou a embebição e germinação de $S$. saponaria (Tabela 1). A absorção de $\mathrm{HgO}$ pela semente pode ter sido limitada em virtude da baixa solubilidade em água (de 0,052 g.L.-1 a $25^{\circ} \mathrm{C}$ ) e alta densidade (de $11,1 \mathrm{~g} / \mathrm{cm}^{3}$ à $20^{\circ} \mathrm{C}$ ) (Silva e Machado, 2008; Merck Millipore, 2019). É provável que solos contaminados por $\mathrm{HgO}$ possam manter bancos de sementes viáveis. Mais pesquisas sobre a avaliação do banco de sementes e plântulas em ambientes contaminados por metais pesados são recomendadas para melhor compreensão da interação entre contaminante e vegetal.

Os parâmetros das equações geradas para estimar os atributos avaliados após a contagem final apre- 
da Silveira, A. B. et al.

sentaram significância estatística $(p \leq 0,05)$ (Tabela 3 ). O comportamento quadrático foi observado em todos os modelos ajustados. Os coeficientes de determinação ajustados foram elevados (superior a 0,80), exceto para os atributos que envolveram a massa verde. Os valores estimados pelas equações foram semelhantes aos observados conforme teste $t(p>0,05)$.

Tabela 3 - Estatísticas dos ajustes realizados para a estimação dos atributos avaliados após contagem final (30 dias) em plântulas de $S$. saponaria em função de diferentes concentrações de $\mathrm{HgO}$

\begin{tabular}{cccccc}
\hline Atributos & CR & H/DC & MVR & MVPA & MVT \\
\hline $\bar{R}^{2}$ & 0,86 & 0,82 & 0,74 & 0,20 & 0,20 \\
Erro padrão & 14,68 & 0,14 & 0,02 & 0,03 & 0,10 \\
Teste t (p) & $>0,05$ & $>0,05$ & $>0,05$ & $>0,05$ & $>0,05$ \\
\hline$\beta_{0}$ & $100,8346^{*}$ & $0,2787^{*}$ & $0,1429^{*}$ & $0,0874^{*}$ & $1,5529^{*}$ \\
$\beta_{1}$ & $-3623,5574^{*}$ & $29,2443^{*}$ & $-3,5865^{*}$ & $-1,9624^{*}$ & $-6,4496^{*}$ \\
$\beta_{2}$ & $34850,9204^{*}$ & $-275,3404^{*}$ & $32,9591^{*}$ & $20,2160^{*}$ & $72,7029^{*}$ \\
\hline
\end{tabular}

"(p $\leq$ 0,05). " $y=\beta_{0}+\beta_{1} C+\beta_{2} C^{2}$ ", em que "C" foi a concentração de $\mathrm{HgO}$ em g/cm³ de vermiculita. CR = Comprimento da raiz principal. MVR $=$ Massa verde do sistema radicular. MVPA $=$ Massa verde da parte aérea. MVT $=$ Massa verde total.

A presença de mercúrio na vermiculita prejudicou o desenvolvimento das plântulas de S. saponaria (Figuras 1 e 2). Realizando a primeira derivada e igualando a zero as equações geradas, foram obtidos os pontos mínimos de comprimento da raiz principal $(10,40 \mathrm{~mm})$ e das massas verdes do sistema radicular $(0,05 \mathrm{~g})$, da parte aérea $(0,04 \mathrm{~g})$ e total $(1,06 \mathrm{~g})$ re- ferentes às concentrações de $0,0520 \mathrm{~g} / \mathrm{cm}^{3}, 0,0544 \mathrm{~g} /$ $\mathrm{cm}^{3}, 0,0485 \mathrm{~g} / \mathrm{cm}^{3}$ e $0,0444 \mathrm{~g} / \mathrm{cm}^{3}$ de $\mathrm{HgO}$ na vermiculita, respectivamente. O ponto máximo da relação $\mathrm{CPA} /$ CR $(1,06)$ foi na concentração de $0,0531 \mathrm{~g} / \mathrm{cm}^{3}$ de $\mathrm{HgO}$ na vermiculita. Portanto, as concentrações mais tóxicas de $\mathrm{HgO}$ variaram entre 0,4444 e $0,5444 \mathrm{~g} / \mathrm{cm}^{3}$ de $\mathrm{HgO}$ na vermiculita.

Figura 1 - Etapas desde a embebição da semente até o desenvolvimento da plântula de S. saponaria
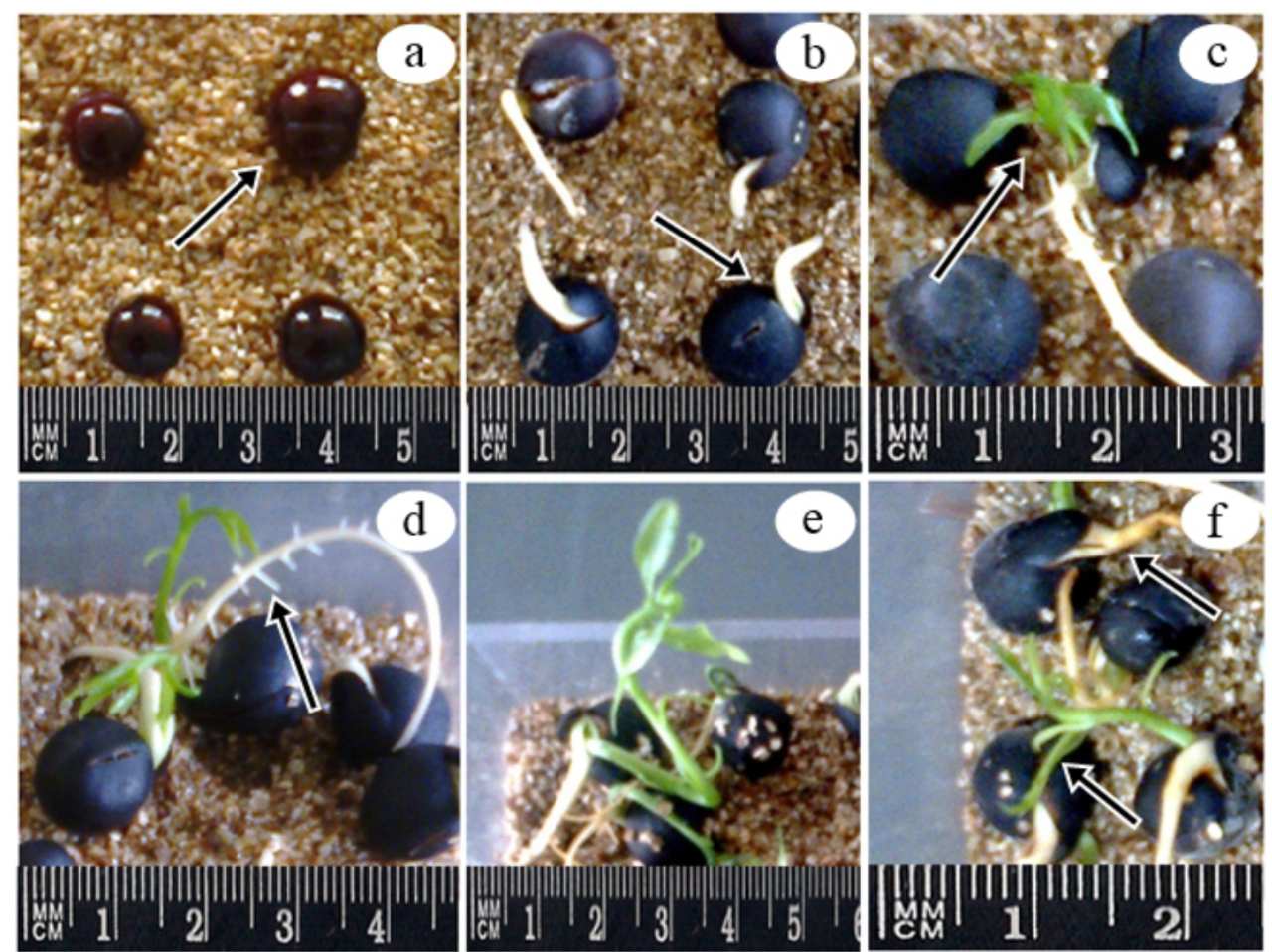

a - embebição após 1 dia; b - germinação (protrusão de radícula) após 5 dias; c - emissão de parte aérea após 8 dias; d - emissão de raízes laterais após 9 dias; e - plântula sadia após 30 dias e; $\mathrm{f}$ - plântula com sintomas de fitotoxidez de $\mathrm{HgO}$ (parte aérea tenra e raízes escuras e atrofiadas) após 30 dias. 
Figura 2 - Atributos avaliados, após contagem final (30 dias), em plântulas de $S$. saponaria em função de diferentes concentrações de $\mathrm{HgO}$
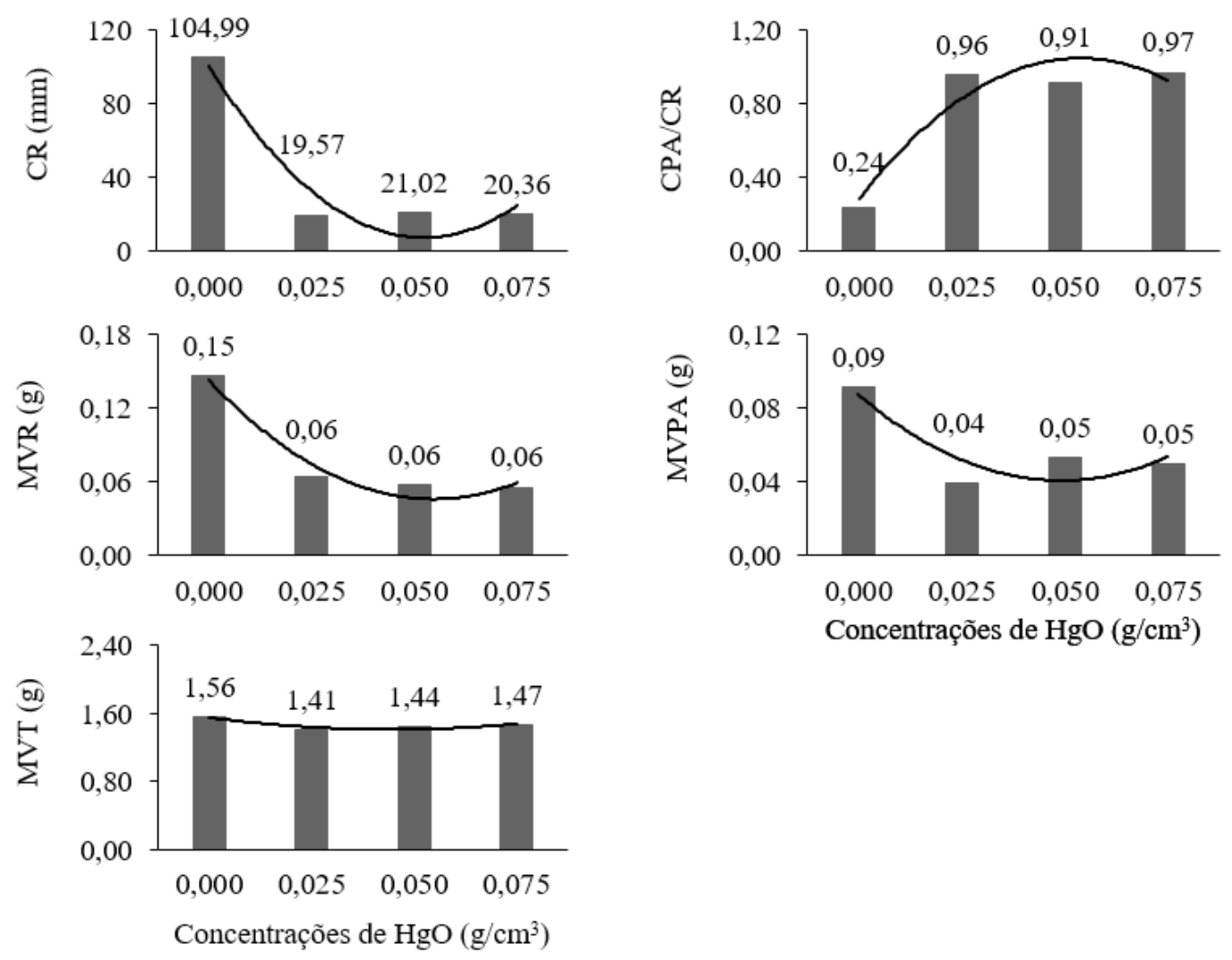

$\mathrm{CR}=$ Comprimento da raiz principal. MVR $=$ Massa verde do sistema radicular. MVPA $=$ Massa verde da parte aérea. MVT $=$ Massa verde total. $\mathrm{CPA}=$ Comprimento da parte aérea.

O primeiro sintoma visível foi o escurecimento e atrofia das raízes à medida que concentrou o $\mathrm{HgO}$ (Figura 1e). De acordo com Oliveira et al. (2001), estes sintomas podem ser resultados de alguma alteração no metabolismo vegetal ou mesmo da acumulação de metal pesado nas raízes. O mercúrio pode causar estresse hídrico no vegetal, reagindo com sulfidrilas livres dentro das aquaporinas, diminuindo sua permeabilidade osmótica em células radiculares (Voicu et al., 2008).

$\mathrm{O} \mathrm{HgO}$ prejudicou o crescimento da raiz principal e acúmulo de massa verde no sistema radicular e de parte aérea vegetal (Figura 2). Concentrações elevadas de mercúrio podem inibir reações metabólicas essenciais para o crescimento vegetal (Voicu et al., 2008). Segundo Boening (2000), o mercúrio pode se acumular nas raízes e limitar a absorção e o transporte de nutrientes e água nas plantas. As concentrações estudadas do metal pesado proporcionaram maior relação entre os comprimentos de parte aérea e de raiz (próximo à 1:1) que a testemunha. Este fenômeno ocorreu devido a formação de raízes atrofiadas naqueles tratamentos com aplicação de $\mathrm{HgO}$, comprometendo, também, o acúmulo de massa verde na parte aérea da plântula.

Também, observou-se amarelecimento das folhas nos tratamentos em que o $\mathrm{HgO}$ foi misturado à vermiculita. O estresse fisiológico de origem hídrica induz a biossíntese do etileno em vegetais (Taiz e Zeiger, 2013), o que justificaria a clorose foliar observada (Goren e Siegel, 1976). O comprimento de parte aérea não foi influenciado pelas concentrações de $\mathrm{HgO}$. Como já esperado, verificou-se fototropismo positivo nas plântulas de $S$. saponaria, que cresceram em direção à luz a fim de manter o equilíbrio fotossintético. Isto se deve, provavelmente, a um transporte de água alternativo às aquaporinas sensíveis ao $\mathrm{Hg}^{2+}$. Segundo Voicu e Zwiazek (2010), o bloqueio desses canais sugere a utilização de uma rota apoplástica para o transporte de água em folhas de Populus. tremuloides Michx. Salienta-se, ainda, que essa rota é influenciada pelo número e atividade das aquaporinas (Neumann, 2008).

A massa verde da parte área decresceu com a concentração de $\mathrm{HgO}$ na vermiculita, gerando caules tenros e frágeis (Figuras 1e e 2). O crescimento em espessura do caule e nas raízes de espécies lenhosas é regulado pela atividade do meristema lateral, atuando na formação de tecidos de revestimento e de sistemas vasculares secundários (Appezzato-da-Glória; Carmello-Guerreiro, 2006). Deste modo, o crescimento secundário das plântulas de $S$. saponaria pode ter sido limitado pelo bloqueio das aquaporinas com o mercúrio, dando origem a caules pouco vigorosos. Outra hipótese que deve ser considerada é a de que o mercúrio possa ter sido adsorvido pela lignina e danificado sua molécula. A lignina por 
da Silveira, A. B. et al.

sua vez, confere estabilidade à parede celular vegetal e possui a capacidade de adsorver íons metálicos como o $\mathrm{Hg}^{2+}, \mathrm{Pb}^{2+}, \mathrm{Cu}^{2+}$ e $\mathrm{Cd}^{2+}$ (Martins et al., 2008; Sanchez et al., 2010; Lv et al., 2012; Rengifo et al., 2013).

A fim de se obter uma estimativa do limite tolerável para a concentração de $\mathrm{HgO}$ na vermiculita que permita o desenvolvimento normal de $S$. saponaria, assumiu-se a diferença entre a média e uma unidade de desvio padrão para cada atributo do tratamento testemunha. A partir das equações obtidas (Tabela 3), as concentrações máximas toleradas pela plântula de $S$. saponaria foram de $0,0045 \mathrm{~g} / \mathrm{cm}^{3}, 0,0099 \mathrm{~g} / \mathrm{cm}^{3}, 0,0147 \mathrm{~g} / \mathrm{cm}^{3}$ e 0,0443 $\mathrm{g} / \mathrm{cm}^{3}$ para o comprimento da raiz principal, massas verdes do sistema radicular, de parte aérea e total, respectivamente. Em relação ao acúmulo de massa verde, o sistema radicular demonstrou maior sensibilidade às crescentes concentrações de $\mathrm{HgO}$.

As plântulas de $S$. saponaria podem tolerar baixas concentrações de $\mathrm{HgO}\left(0,0045 \mathrm{~g} / \mathrm{cm}^{3}\right)$ sem causar maiores danos ao crescimento e massa verde vegetal, podendo ser utilizada como bioindicadora da qualidade ambiental. Mais estudos são necessários para a elucidação dos mecanismos que envolvem a absorção, desintoxicação e armazenamento de metais pesados por plantas, pois podem ser utilizados para o desenvolvimento de mate- riais genéticos adequados para fitorremediação (Milner e Kochian, 2008).

\section{Conclusão}

A dormência das sementes de $S$. saponaria pode ser superada com a escarificação mecânica do tegumento com esmeril elétrico.

A germinação de sementes de $S$. saponaria não é influenciada pela presença de mercúrio no substrato vermiculita.

S. saponaria tolera baixas concentrações de $\mathrm{HgO}$ em vermiculita $\left(0,0045 \mathrm{~g} / \mathrm{cm}^{3}\right)$ sem causar maiores danos ao seu crescimento e acúmulo de massa verde, podendo ser utilizada como bioindicadora da qualidade ambiental em sítios sujeitos à contaminação por mercúrio.

Sintomas de fitotoxicidade de $\mathrm{HgO}$ em plântulas de $S$. saponaria são caracterizados pela formação de raízes escuras e atrofiadas, caules tenros e folhas amareladas.

\section{Agradecimentos}

Ao Instituto Federal de Educação, Ciência e Tecnologia de Minas Gerais - Campus São João Evangelista pelo apoio e infraestrutura para a realização deste trabalho.

\section{Referências}

Albiero, A. L. M.; Bacchi, E. M.; Mourão, K. S. M. 2001. Caracterização anatômica das folhas, frutos e sementes de Sapindus saponaria L. (Sapindaceae). Acta Scientiarum, 23: 549-560. Doi: https://doi. org/10.4025/actascibiolsci.v23i0.2733.

Appezzato-da-Glória, B.; Carmello-Guerreiro, S. N. 2006. Anatomia Vegetal, Viçosa, UFV.

Boening, D. W. 2000. Ecological effects, transport, and fate of Mercury: a general review. Chemosphere, 40: 1335-1351. Doi: https://doi. org/10.1016/S0045-6535(99)00283-0.

Brasil. 2009. Regras para análise de sementes. Ministério de Agricultura, Pecuária e Abastecimento. Secretaria Nacional de Defesa Agropecuária, Brasília: Mapa/ACS.

Cicatelli, A.; Todeschini, V.; Biondi, S.; Torrigiani, P.; Castiglione, S. 2010. Arbuscular mycorrhizal fungi restore normal growth in a white poplar clone grown on heavy metal-contaminated soil, and this is associated with upregulation of foliar metallothionein and polyamine biosynthetic gene expression. Annals of Botany, 106: 791-802. Doi: https://doi.org/10.1093/aob/mcq170.

Climate-data.org. 2019. Clima: São João Evangelista. Disponível em: https://pt.climate-data.org/location/175926/.

Conn, S.; Gilliham, M. 2010. Comparative physiology of elemental distributions in plants. Annals of Botany, 105: 1081/102. Doi: https:// doi.org/10.1093/aob/mcq027.
Cook, A.; Turner, S. R.; Baskin, J. M.; Baskin, C. C.; Steadman, K. J.; Dixon, K. W. 2008. Occurrence of physical dormancy in seeds of Australian Sapindaceae: a survey of 14 species in nine genera. Annals of Botany, 101: 1349-1362. Doi: https://doi.org/10.1093/aob/mcn043.

Copete, E.; Herranz, J. M.; Ferrandis, P.; Baskin, C. C.; Baskin, J. M. 2011. Physiology, morphology and phenology of seed dormancy break and germination in the endemic Iberion species Narcissus hispanicus (Amaryllidaceae). Annals of Botany, 107: 1003-1016. Doi: https://doi. org/10.1093/aob/mcr030.

Damas, G. B.; Bertoldo, B.; Costa, L. T. 2014. Mercúrio: da antiguidade aos dias atuais. Revista Virtual Quimica, 6: 1010-1020. Doi: https:// doi.org/10.5935/1984-6835.20140063.

Freitas, A. R.; Lopes, J. C.; Matheus, M. T.; Mengarda, L. H. G.; Venancio, L. P.; Caldeira, M. V. W. 2013. Superação da dormência de sementes de jatobá. Pesquisa Florestal Brasileira, 33: 85-90. Doi: https://doi. org/10.4336/2013.pfb.33.73.350.

Goren, R.; Siegel, S. M. 1976. Mercury-induced ethylene formation and abscission in Citrus and Coleus explants. Plant Physiology, 57: 628-631. Doi: https://doi.org/10.1104/pp.57.4.628.

Grisi, P. U.; Gualtieri, C. J.; Ranal, M. A.; Santana, D. G. 2013. Phytotoxic activity of crude aqueous extracts and fractions of young leaves of Sapindus saponaria L. (Sapindaceae). Acta Botanica Brasilica, 27: 62-70. Doi: http://dx.doi.org/10.1590/S0102-33062013000100009.

Kehrig, H. A.; Malm, O.; Palermo, E. F. A.; Seixas, T. G.; Baêta, A. P; Moreira, I. 2011. Bioconcentração e biomagnificação de metilmercúrio na baía de Guanabara, Rio de Janeiro. Química Nova, 34: 377-384. Doi: http://dx.doi.org/10.1590/S0100-40422011000300003. 
Kenderesová, L.; Stanová, A.; Pavlovkin, J., Durisová, E.; Nadubinská, M.; Ciamporová, M.; Ovecka, M. 2012. Early $\mathrm{Zn}^{2+}$-induced effects on membrane potential account for primary heavy metal susceptibility in tolerant and sensitive Arabidopsis species. Annals of Botany, 110: 445-459. Doi: https://doi.org/10.1093/aob/mcs111.

van Klinken, R. D.; Lukitsch, B.; Cook, C. 2008. Interaction between seed dormancy-release mechanism, environment and seed bank strategy for a widely distributed perennial legume, Parkinsonia aculeata (Caesalpinaceae). Annals of Botany, 102: 255-264. Doi: https://doi. org/10.1093/aob/mcn087.

van Klinken, R. D; Flack, L. 2005. Wet heat as a mechanism for dormancy release and germination of seeds with physical dormancy. Weed Science, 53: 663-669. Doi: https://doi.org/10.1614/WS-05-008R.1.

Lv, J.; Luo, L.; Zhang, J.; Christie, P.; Zhang, S. 2012. Adsorption of mercury on lignin: combined surface complexation modeling and X-ray absorption spectroscopy studies. Environmental Pollution, 162: 255261. Doi: https://doi.org/10.1016/j.envpol.2011.11.012.

Maguire, J. D. 1962. Speed of germination aid in selection and evaluation for seedling and vigor. Crop Science, 2: 176-177. Doi: http://dx.doi. org/10.2135/cropsci1962.0011183X000200020033x.

Marmiroli, M.; Pietrini, F.; Maestri, E.; Zacchini, M.; Marmiroli, N.; Massaci, A. 2011. Growth, physiological and molecular traits in Salicaceae trees investigated for phytoremediation of heavy metals and organics. Tree Physiology, 31: 1319-1334. Doi: https://doi.org/10.1093/ treephys/tpr090.

Martins, G. F.; Pereira, A. A.; Stracçalano, B. A.; Antunes, P. A.; Pasquini, D.; Curvelo, A. A. S.; Ferreira, M.; Riul J. R. A.; Constatino, C. J. L. 2008. Ultrathin films of lignins as a potential transducer in sensing applications involving heavy metal ions. Sensors and Actuators B, 129: 525-530. Doi: https://doi.org/10.1016/j.snb.2007.08.051.

Merck Millipore. 2019. 104466 Óxido de Mercúrio (II). Disponível em: http://www.merckmillipore.com/brazil/chemicals/oxido-de-mercurioii/ MDA_CHEM-104466/p_ygib.s1LBqcAAAEWD.EfVhTl.

Milner, M. J.; Kochian, L. V. 2008. Investigating heavy-metal hiperaccumulation using Thlaspi caerulescens as a model system. Annals of Botany, 102: 3-13. Doi: https://doi.org/10.1093/aob/mcn063.

Micaroni, R. C. C. M.; Bueno, M. I. M. S.; Jardim, W. F. 2000. Compostos de mercúrio. Revisão de métodos de determinação, tratamento e descarte. Química Nova, 23: 487-495. https://dx.doi.org/10.1590/ S0100-40422000000400011

Neumann, P. M. 2008. Coping mechanisms for crop plants in droughtprone environments. Annals of Botany, 101: 901-907. Doi: https://doi. org/10.1093/aob/mcn018.

Noriega-Luna, B.; Morales-Rodríguez, A. A.; Luna-Quintanilla, R.; Ulloa-Vásquez, T.; Cruz-Jiménez, G. C.; Serafín-Muñoz, A. H.; GutiérrezOrtega, N. L. 2016. Identificación de especies vegetales asociadas a jales del distrito minero de Guanajuato. Acta Universitaria, 26: 71-77. Doi: https://doi.org/10.15174/au.2016.1465.

Oliveira, J. A.; Cambraia, J.; Cano, M. A. O.; Jordão, C. P. 2001. Absorção e acúmulo de cádmio e seus efeitos sobre o crescimento relativo de plantas de aguapé e de salvínia. Revista Brasileira de Fisiologia Vegetal, 13: 329-341. Doi: http://dx.doi.org/10.1590/S0103-31312001000300008.

Oliveira, L. M.; Bruno, R. L. A.; Silva, K. R. G.; Silva, V. D. M.; Ferrari, C. S.; Silva, G. Z. 2012. Germinação e vigor de sementes de Sapindus saponaria l. submetidas a tratamentos pré-germinativos, temperaturas e substratos. Ciência Rural, 42: 638-644. Doi: http://dx.doi.org/10.1590/ S0103-84782012000400010.
R Core Team. 2018. R: A language and environment for statistical computing. Vienna: R Foundation for Statistical Computing.

Rashed, K. N.; Ciric, A.; Glamoclija, J.; Calhelha, R. C.; Ferreira, I. C. F. R.; Sokovic, M. 2013. Antimicrobial and activity, growth inhibition of human tumour cell lines, and phytochemical characterization of the hydromethanolic extract obtained from Sapindus saponaria L. aerial parts. BioMed Research International, 2013: 1-9. Doi: http://dx.doi. org/10.1155/2013/659183.

Rengifo, V. E. G.; Jiménez, J. A. V.; Marín, G. C. Q. 2013. Lignina como adsorbente de metales pesados. Revista Investigaciones Aplicadas, 7: 74-85. Disponível em: https://revistas.upb.edu.co/index.php/ investigacionesaplicadas/article/view/1756/1967.

Sanchez, E. M. S.; Cavani, C. S.; Leal, C. V.; Sanchez, C. G. 2010. Compósito de resina de poliéster insaturado com bagaço de canade-açúcar: influência do tratamento das fibras nas propriedades. Polímeros, 20: 194-200. Doi: http://dx.doi.org/10.1590/S010414282010005000034.

Silva, K. A.; Martins, S. V.; Neto, A. M.; Demolinari, R. A.; Lopes, A. T. 2016. Restauração Florestal de uma Mina de Bauxita: Avaliação do Desenvolvimento das Espécies Arbóreas Plantadas. Revista Floresta e Ambiente, 23: 309-319. Doi: http://dx.doi.org/10.1590/21798087.142515.

Silva, R. R.; Machado, P. F. L. 2008. Experimentação no ensino médio de química: a necessária busca da consciência ético-ambiental no uso e descarte de produtos químicos - um estudo de caso. Ciência \& Educação, 14: 233-249. Doi: http://dx.doi.org/10.1590/S151673132008000200004 .

Taiz, L.; Zeiger, E. 2013. Fisiologia vegetal. 5. ed. Porto Alegre, Artmed.

Toorop, P. E.; Cuerva, R. C.; Begg, G. S.; Locardi, B.; Squire, G. R.; Iannetta, P.P. M. 2012. Co-adaptation of seed dormancy and flowering time in the arable weed Capsella Bursa-pastoris (shepherd's purse). Annals of Botany, 109: 481-489. Doi: https://doi.org/10.1093/aob/ mcr301.

Turner, S. R.; Cook, A.; Baskin, J. M.; Baskin, C. C.; Tuckett, R. E.; Steadman, K. J.; Dixon, K. W. 2009. Identification and characterization of the water gap in the physically dormant seed of Dodonaea petiolaris: a first report for Sapindaceae. Annals of Botany, 104: 833-844. Doi: https://doi.org/10.1093/aob/mcp171.

Voicu, M. C.; Zwiazek, J. J. 2010. Inhibitor studies of leaf lamina hydraulic conductance in trembling aspen (Populus tremuloides Michx.) leaves. Tree Physiology, 30: 193-204. Doi: https://doi.org/10.1093/ treephys/tpp112.

Voicu, M. C.; Zwiazek, J. J.; Tyree, M. 2008. Light response of hydraulic conductance in bur oak (Quercus macrocarpa) leaves. Tree Physiology, 28: 1007-1015. Doi: https://doi.org/10.1093/treephys/28.7.1007.

Wagmann, K.; Hautekèete, N. C.; Piquot, Y.; Meunier, C.; Schmitt, S. E.; Dijk, H. V. 2012. Seed dormancy distribution: explanatory ecological factors. Annals of Botany, 110: 1205-2019. Doi: https:// doi.org/10.1093/aob/mcs194.

White, P. J.; Brown, P. H. 2010. Plant nutrition for sustainable development and global health. Annals of Botany, 105: 1073-1080. Doi: https://doi.org/10.1093/aob/mcq085. 